\title{
Modeling of transport phenomena in continuous casting of non-dendritic billets
}

\author{
Arvind Kumar, Pradip Dutta * \\ Department of Mechanical Engineering, Indian Institute of Science, Bangalore 560 012, India
}

\begin{abstract}
A macroscopic model for simulating the phase change process and transport of solid fraction is developed for the case of solidification during direct chill continuous casting of a non-dendritic Al-alloy billet, in presence of electromagnetic stirring. Maxwell's equations are solved to obtain the electromagnetic force field, which is incorporated in the momentum conservation equations as body force source terms. Thereafter, the complete set of equivalent single-phase governing equations (mass, momentum, energy, species conservation and transport of solid fraction) are solved using a pressure-based finite volume method. A variable viscosity approach is employed to model fluid flow in presence of phase change. The model is first validated against some experimental and numerical results available in the literature, pertaining to the case of conventional continuous casting without any externally imposed stirring. The model predicts the temperature, velocity, species and most importantly, the solid fraction distribution in the mold. These predictions are then used for studying the influence of initial superheat, stirring intensity and cooling rate on the macroscopic behavior of the system.
\end{abstract}

Keywords: Solidification; Modeling; Macroscopic; Non-dendritic; Electromagnetic stirring

\section{Introduction}

In several applications of casting, dendritic microstructure is not desirable as it results in poor mechanical properties. Enhancing the fluid flow in the mushy zone by stirring is one of the means to suppress this dendritic growth $[1,2]$. The strong fluid flow detaches the dendrites from the solid-liquid interface and carries them into the mold to form a slurry. This slurry has globular solid

\footnotetext{
* Corresponding author. Tel.: +91 802293 3225; fax: +91 80 23604536.

E-mail address: pradip@mecheng.iisc.ernet.in (P. Dutta).
}

phase consisting of fragmented dendrites, instead of the conventional dendritic structure, immersed in liquid. When this slurry solidifies, the microstructure is characterized by globular, non-dendritic primary phase particles, separated and enclosed by a near-eutectic lower-melting second phase [1]. The globulatic microstructures, when partially remelted, offers less resistance to flow even at a high solid fraction. This property represents a great potential for further processing in a semi-solid state by various forming techniques such as pressure die casting and forging. The above principle is the basis of a new manufacturing technology called "semi-sold forming" (SSF), in which metal alloys are cast in the semi-solid state [1]. 


\begin{tabular}{|c|c|c|c|}
\hline \multicolumn{4}{|c|}{ Nomenclature } \\
\hline$a_{\mathrm{P}}, a_{\mathrm{P}}^{0}$ & coefficient in discretization equation & \multicolumn{2}{|c|}{ Greek symbols } \\
\hline$B$ & magnetic flux density $\left(\mathrm{Wb} \mathrm{m}^{-2}\right)$ & $\alpha$ & thermal diffusivity $\left[\mathrm{m}^{2} \mathrm{~s}^{-1}\right]$ \\
\hline$C$ & species concentration & $\beta_{\mathrm{T}}$ & thermal expansion coefficient $\left[\mathrm{K}^{-1}\right]$ \\
\hline$c$ & specific heat $\left[\mathrm{J} \mathrm{kg}^{-1} \mathrm{~K}^{-1}\right]$ & $\beta_{\mathrm{S}}$ & solutal expansion coefficient \\
\hline$D$ & $\begin{array}{l}\text { mass diffusion coefficient of the species } \\
{\left[\mathrm{m}^{2} \mathrm{~s}^{-1}\right]}\end{array}$ & & dynamic viscosity $\left[\mathrm{kg} \mathrm{m}^{-1} \mathrm{~s}^{-1}\right]$ \\
\hline$E$ & electric field $\left(\mathrm{V} \mathrm{m}^{-1}\right)$ & $\begin{array}{l}\mu_{\mathrm{p}} \\
\rho\end{array}$ & density $\left[\mathrm{kg} \mathrm{m}^{-3}\right]$ \\
\hline$F$ & Lorentz force $\left[\mathrm{N} \mathrm{m}^{-3}\right]$ & $\sigma_{\mathrm{e}}$ & electrical conductivity $\left[\mathrm{mho} \mathrm{m}^{-1}\right.$ ] \\
\hline$f$ & weight fraction & & \\
\hline$g$ & acceleration due to gravity $\left[\mathrm{m}^{2} \mathrm{~s}^{-1}\right]$ & \multicolumn{2}{|c|}{ Subscripts } \\
\hline$H$ & enthalpy $\left[\mathrm{J} \mathrm{kg}^{-1}\right]$ & $\mathrm{E}$ & eutectic \\
\hline$\Delta H$ & latent enthalpy $\left[\mathrm{J} \mathrm{kg}^{-1}\right]$ & $\mathrm{g}$ & generation \\
\hline$J$ & current density $\left[\mathrm{A} \mathrm{m}^{-2}\right]$ & $\mathrm{i}$ & initial \\
\hline$k$ & thermal conductivity [ $\mathrm{W} \mathrm{m} \mathrm{m}^{-1} \mathrm{~K}^{-1}$ ] & $\mathrm{L}$ & liquidus \\
\hline$k_{\mathrm{n}}$ & partition coefficient & 1 & liquid phase \\
\hline$L$ & latent heat of fusion $\left[\mathrm{J} \mathrm{kg}^{-1}\right]$ & $\mathrm{m}$ & melting \\
\hline$r$ & radius $[\mathrm{m}]$ & $\mathrm{o}$ & old time step value \\
\hline$S$ & source term & $\mathrm{S}$ & solidus \\
\hline$t$ & time $[\mathrm{s}]$ & s & solid phase \\
\hline$T$ & temperature $\left[{ }^{\circ} \mathrm{C}\right]$ & ref & reference \\
\hline$u, v$ & velocities in $z$, and $r$ directions $\left[\mathrm{m} \mathrm{s}^{-1}\right]$ & $r$ & radial \\
\hline$u$ & continuum velocity vector $\left[\mathrm{m} \mathrm{s}^{-1}\right]$ & $z$ & axial \\
\hline$u_{\text {cast }}$ & withdrawal speed of the billet $\left[\mathrm{m} \mathrm{s}^{-1}\right]$ & & \\
\hline$u_{\text {in }}$ & velocity at inlet $\left[\mathrm{m} \mathrm{s}^{-1}\right]$ & & \\
\hline$r, z$ & coordinate axes [m] & & \\
\hline
\end{tabular}

Among the various techniques to produce non-dendritic billets, electromagnetic stirring (EMS) is, perhaps, the most popular one as it is non-intrusive and offers adequate flexibility on the mode of stirring [1,3]. The growing dendrites are sheared off from the solidification interface by the rotating liquid and then transported into the bulk liquid. It is mentioned in [1] that the possible causes of dendrite detachment include dendrite arm fracture due to shearing action and dissolution of dendrite arms. Fragmentation of dendrites is governed by both these mechanisms, but the primary cause is the shearing action of the dendrites arms. Some of the dendrites are remelted and disappear while others survive and form a semi-solid slurry in the melt. These surviving broken dendrites then form additional nucleation sites upon which further grain growth will occur, thereby resulting in grain refinement in the final casting products.

Although considerable research has been done on optimizing the forming techniques in SSF and the specific globular microstructure of the feedstock material $[1,3,4]$, not much is known about the solidification process and distinct flow behavior of the semi-solid slurries during feedstock preparation. The solidification process will significantly influence the quality of the formed part. Casting of semi-solid billets depends on many parameters, such as the stirring intensity, cooling rate, initial superheat and rate of billet withdrawal. A minimum shear rate should be produced by the EMS system so that dendrites can detach from their roots. The position of the stirrer in the mold is also important. Therefore, it is essential to understand the interrelationship among these parameters to design an effective semi-solid billet casting facility. Development of a computational model, which can predict the temperature, velocity, composition and solid fraction distribution in the mold, is an important step towards systematic design of a semi-solid billet casting facility.

Till date, there have been very few attempts on numerical modeling of the semi-solid billet casting process. Garat et al. [4] and Gabathuler et al. [5] reviewed the various casting technologies for feedstock billet production, such as electromagnetic stirring, mechanical stirring and chemical refinement. There are mainly three variants of electromagnetic stirring exist on a commercial scale: linear stirring, rotary stirring and helicoidal stirring [5]. A comprehensive review of literature on the use of electromagnetic stirring in continuous casting of steel was presented by Moore [6]. It has been shown that a velocity on the order $0.25 \mathrm{~m} \mathrm{~s}^{-1}$ near the solidification front detaches the dendrites and effects the columnar-equiaxed transition in steel casting. Vives [3] discussed the working principle of electromagnetic 
rheocasters which are based on the use of rotating permanent magnets and which allow the production of intense stirring in the solidifying alloy slurries. Local measurement techniques were applied to the study of the evolution of the electromagnetic, hydrodynamic, and thermal phenomena with time inside vigorously agitated melt-solid mixtures. Vives [7] extended the above electromagnetic design to 3-D multiphase flows in solidifying semi-solid alloy slurries and metal matrix composites. Roplekar and Dantzig [8] proposed a three dimensional mathematical model of the casting process in presence of MHD stirring, and implemented the formulation using a finite element method. A rotating magnetic field was applied during solidification to produce billets having a desired microstructure in continuously cast round sections. Prescott and Incropera [9] studied the effect of turbulence on solidification of $\mathrm{Pb}-19 \mathrm{wt} \%$ $\mathrm{Sn}$ alloy where electromagnetic induction is considered as a means of altering the convection during solidification. Gebelin et al. [10] considered an isothermal twophase model using finite element method in order to predict macrosegregation occurring during thixoforming of metallic alloys.

In the present work we describe a numerical approach for the study of transport phenomena in semi-solid billet casting process. A finite-volume based single-phase continuum model is used to simulate the phase change phenomena. A variable viscosity approach [11] is used to model the fluid flow accompanied by phase change. A separate solid fraction transport equation is used to simulate the transport of fragmented dendrites in the slurry. The model is first validated against experimental results [12] and simulation results [13] for the case of conventional continuous casting of an Al$4.5 \mathrm{wt} \% \mathrm{Cu}$ round ingot without any stirring. The validated model is then extended appropriately to predict the steady state velocity, temperature, species, and solid fraction distribution in the mold. Finally, the effects of the important parameters (such as initial superheat, stirring intensity and cooling rate) on the macroscopic behavior of the process are studied.

\section{Description of the physical process}

The non-dendritic billet casting, also known as "semi-solid" billet casting, is similar to the conventional direct chilled continuous casting process in many ways. However, unlike in a conventional continuous casting process, it is also subjected to a stirring (e.g. EMS) in order to shear off the dendrites in the mushy zone. A schematic diagram of a typical semi-solid billet casting process with EMS is illustrated in Fig. 1. The stirrer design entails the placement of a stack of coils around the mold to generate a primary motion that recirculates along the longitudinal direction. In the case of a linear stirring system as shown in Fig. 1, the dendrites located near the solidification front are recirculated up to the hotter zone of the stirring chamber and partially remelted. The molten metal is poured continuously into the mold through an opening at the top with an inlet velocity, $u_{\text {in }}$, and the solid billet is drawn away at a constant casting speed, $u_{\text {cast }}$.

For the present case study, the alloy chosen is Al$4.5 \mathrm{wt} \% \mathrm{Cu}$, and the diameter of the billet is $53.34 \mathrm{~cm}$. The melt enters the mold with a temperature of $707^{\circ} \mathrm{C}$

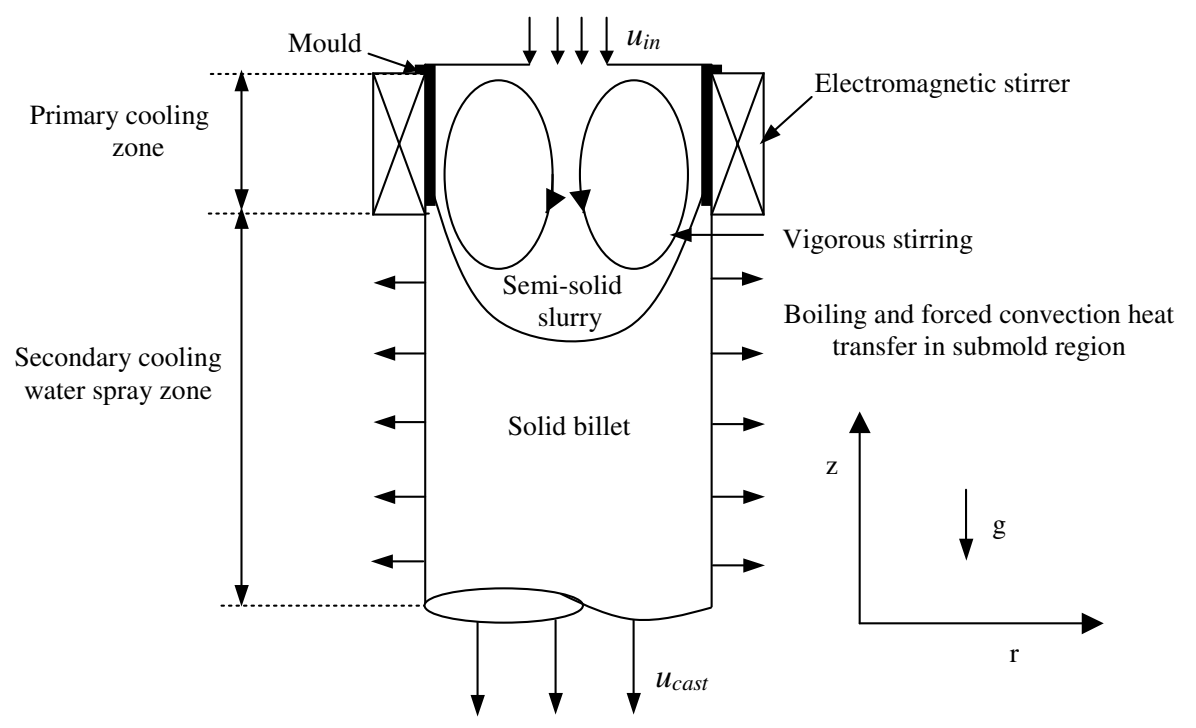

Fig. 1. Schematic illustration of semi-solid billet casting process. 
Table 1

Thermophysical properties and system data [13]

\begin{tabular}{|c|c|}
\hline \\
\hline \multicolumn{2}{|l|}{$\begin{array}{l}\text { Properties } \\
\text { Density of the solid phase }\left(\rho_{\mathrm{s}}\right)\end{array}$} \\
\hline Density of the liquid phase $\left(\rho_{1}\right)$ & $2580.0 \mathrm{~kg} \mathrm{~m}^{-3}$ \\
\hline $\begin{array}{l}\text { Dynamic viscosity of the } \\
\text { pure liquid }(\mu)\end{array}$ & $0.0012 \mathrm{~N} \mathrm{~s} \mathrm{~m}^{-2}$ \\
\hline $\begin{array}{l}\text { Thermal conductivity of the } \\
\text { liquid phase }\left(k_{1}\right)\end{array}$ & $57.3 \mathrm{~W} \mathrm{~m}^{-1} \mathrm{~K}^{-1}$ \\
\hline $\begin{array}{l}\text { Thermal conductivity of the } \\
\text { liquid phase }\left(k_{\mathrm{s}}\right)\end{array}$ & $120.7 \mathrm{~W} \mathrm{~m}^{-1} \mathrm{~K}^{-1}$ \\
\hline $\begin{array}{l}\text { Specific heat of the } \\
\text { liquid phase }\left(c_{\mathrm{pl}}\right)\end{array}$ & $1179.0 \mathrm{~J} \mathrm{~kg}^{-1} \mathrm{~K}^{-1}$ \\
\hline $\begin{array}{l}\text { Specific eat of the } \\
\text { liquid phase }\left(c_{\mathrm{ps}}\right)\end{array}$ & $1032.0 \mathrm{~J} \mathrm{~kg}^{-1} \mathrm{~K}^{-1}$ \\
\hline Latent heat of fusion $(L)$ & $392 \times 10^{3} \mathrm{~J} \mathrm{~kg}^{-1}$ \\
\hline $\begin{array}{l}\text { Mass diffusivity of the } \\
\text { liquid phase }\left(D_{1}\right)\end{array}$ & $5.0 \times 10^{-9} \mathrm{~m}^{2} \mathrm{~s}^{-1}$ \\
\hline $\begin{array}{l}\text { Mass diffusivity of the } \\
\text { solid phase }\left(D_{\mathrm{s}}\right)\end{array}$ & $8.0 \times 10^{-13} \mathrm{~m}^{2} \mathrm{~s}^{-1}$ \\
\hline Partition coefficient $\left(k_{\mathrm{p}}\right)$ & 0.173 \\
\hline Eutectic temperature $\left(T_{\mathrm{e}}\right)$ & $548^{\circ} \mathrm{C}$ \\
\hline $\begin{array}{l}\text { Eutectic species concentration } \\
\qquad\left(C_{\mathrm{e}}\right)(\mathrm{wt} \% \mathrm{Cu})\end{array}$ & 32.7 \\
\hline $\begin{array}{l}\text { Melting temperature } \\
\text { of "solvent" }\left(T_{\mathrm{m}}\right)\end{array}$ & $660^{\circ} \mathrm{C}$ \\
\hline $\begin{array}{l}\text { Thermal coefficient of volumetric } \\
\text { expansion }\left(\beta_{\mathrm{T}}\right)\end{array}$ & $2.0 \times 10^{-5} \mathrm{~K}^{-1}$ \\
\hline $\begin{array}{l}\text { Solutal coefficient of } \\
\quad \text { volumetric expansion }\left(\beta_{\mathrm{S}}\right)\end{array}$ & 0.025 \\
\hline System data & \\
\hline Ingot diameter & $53.34 \times 10^{-2} \mathrm{~m}$ \\
\hline Diameter of inlet & $0.127 \mathrm{~m}$ \\
\hline Casting speed & $5.33 \times 10^{-4} \mathrm{~m} \mathrm{~s}^{-1}$ \\
\hline Pour temperature & $707^{\circ} \mathrm{C}$ \\
\hline Initial temperature $\left(T_{\mathrm{i}}\right)$ & $707^{\circ} \mathrm{C}$ \\
\hline Composition of pour $(\mathrm{wt} \% \mathrm{Cu})$ & 4.5 \\
\hline Initial composition $\left(C_{\mathrm{i}}\right)$ & 4.5 \\
\hline Inlet temperature of cooling water & $25^{\circ} \mathrm{C}$ \\
\hline $\begin{array}{l}\text { Cooling water flow rate per } \\
\text { unit ingot circumference }\end{array}$ & $0.116 \mathrm{~m}^{2} \mathrm{~h}^{-1}$ \\
\hline
\end{tabular}

(i.e. with $62{ }^{\circ} \mathrm{C}$ superheat). The cooling configuration used in the casting of a semi-solid billet is similar to that of a typical continuous casting system, as illustrated in Fig. 1. The mold is cooled by a primary cooling water jacket. For secondary cooling of the billet, the primary cooling water is jetted out near the bottom of the mold to impinge directly on the emerging surface of the casting and provides cooling by nucleate boiling and forced convection. The water enters the mold at $25^{\circ} \mathrm{C}$ with a flow rate of $0.116 \mathrm{~m}^{3} \mathrm{~h}^{-1} \mathrm{~m}^{-1}$ of billet circumference. The solid billet is withdrawn at the bottom at a casting speed of $3.81 \mathrm{~cm} \mathrm{~min}^{-1}$. The system data, billet diameter and the thermophysical properties used in the simulations are taken from [13], in which corresponding results for conventional continuous casting are available. The relevant data are summarized in Table 1.

\section{Mathematical formulation}

Although several mathematical models are available in the literature addressing the solidification processes in ingot and conventional continuous casting operations, there is hardly any published literature on CFD simulation of semi-solid casting of billets. The main difficulty is in creating a numerical model simulating the fragmentation of dendrites and their transport in the melt due to the stirring action. It is believed that the detachment of dendrites is caused primarily by shear force [1], and the process is further aided by dissolution. The calculation of the shear force required for fracture at the dendrite roots is beyond the scope of our CFD modeling. In order to overcome this problem, we adopt the following procedure. First, we make use of an existing single-phase macroscopic solidification model $[11,14,15]$ to simulate the solidification process in our chosen geometry, similar to a conventional direct chill continuous casting operation. Next, we assume that the stirring action is strong enough to break the dendrites as soon as they form at the solid-liquid interface. These fragmented dendrite particles will now be carried away by the stirred melt. We now make one more simplifying assumption that the fragmented particles travel with the same velocity as that of the fluid. A separate solid fraction transport equation is then written to account for the transport of the fragmented dendrites, in addition to the usual conservation equations for mass, momentum, energy and species. We specify the viscosity, $\mu$, as a function of solid fraction to model the rheological behavior of the semi-solid slurry [1,11]. In the present model the resistance to the fluid flow offered by fragmented dendrites is completely represented by a viscosity-solid fraction variation as shown in Fig. 2.

From the velocity distribution, we can make an estimate of the magnitude of the shear rate near the interface. If the predicted shear rate is more than the required level reported in [1], it is concluded that the stirring produced by the EMS is sufficiently strong.

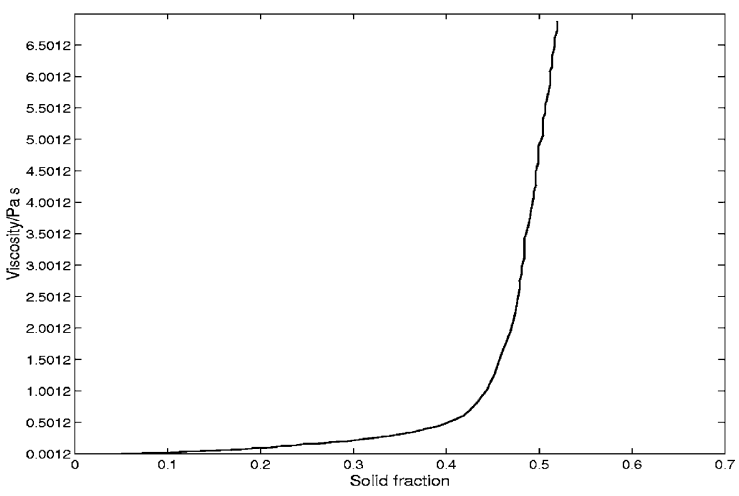

Fig. 2. Variation of viscosity with solid fraction [1]. 


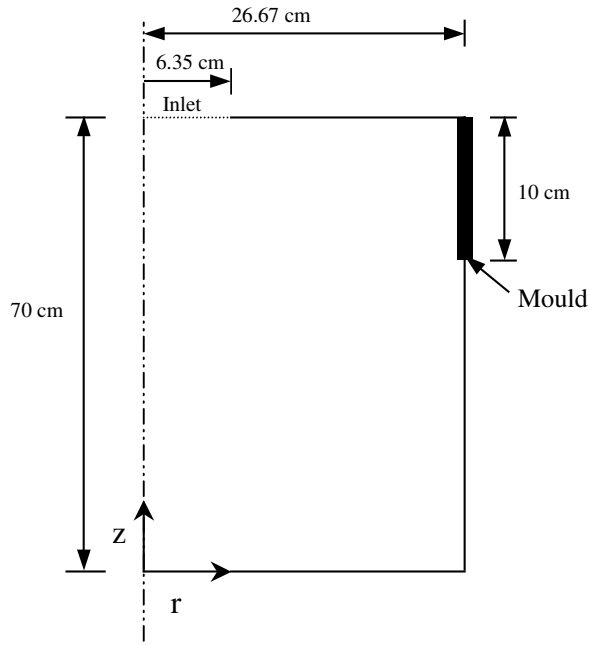

Fig. 3. Schematic illustration of the domain.

Otherwise, the strength of the EMS stirring is adjusted accordingly and the whole procedure is repeated.

For the purpose of developing the model, we choose a standard design given in [13], as shown in Fig. 1. The corresponding axisymmetric domain used in simulations is shown in Fig. 3, together with the relevant dimensions. The governing transport equations for incompressible flow in an axisymmetric geometry for the system considered are as follows.

\subsection{Conservation of mass}

The single-phase continuity equations can be expressed as

$\frac{\partial}{\partial t}(\rho)+\frac{\partial(\rho u)}{\partial z}+\frac{1}{r} \frac{\partial(\rho r v)}{\partial r}=0$.

\subsection{Conservation of linear momentum}

The single-phase momentum equations can be expressed as

$z$-momentum equation:

$$
\begin{aligned}
\frac{\partial}{\partial t}(\rho u) & +\frac{1}{r} \frac{\partial}{\partial z}(r \rho u u)+\frac{1}{r} \frac{\partial}{\partial r}(r \rho u v) \\
=- & \frac{\partial p}{\partial z}+\frac{\partial}{\partial z}\left(\mu \frac{\partial u}{\partial z}\right)+\frac{1}{r} \frac{\partial}{\partial r}\left(\mu r \frac{\partial u}{\partial r}\right) \\
& +\rho g \beta_{\mathrm{T}}\left(T-T_{\text {ref }}\right)+\rho g \beta_{\mathrm{S}}\left(C_{1}-C_{\text {ref }}\right)+F_{z},
\end{aligned}
$$

$r$-momentum equation:

$$
\begin{aligned}
& \frac{\partial}{\partial t}(\rho v)+\frac{1}{r} \frac{\partial}{\partial z}(r \rho u v)+\frac{1}{r} \frac{\partial}{\partial r}(r \rho v v) \\
& \quad=-\frac{\partial p}{\partial r}+\frac{\partial}{\partial z}\left(\mu \frac{\partial v}{\partial z}\right)+\frac{1}{r} \frac{\partial}{\partial r}\left(\mu r \frac{\partial v}{\partial r}\right)+F_{r}-\mu \frac{v}{r^{2}} .
\end{aligned}
$$

In Eqs. (2) and (3) $F_{r}$ and $F_{z}$ are the Lorentz force components, produced by the electromagnetic stirring system.

\subsection{Energy equation}

Similarly, the single-phase energy equations can be written as

$\frac{\partial}{\partial t}(\rho H)+\nabla \cdot(\rho \boldsymbol{u} H)=\nabla \cdot(k \nabla T)$,

where $H$ is the enthalpy of the mixture, and is defined as

$H=h_{\mathrm{s}}+\Delta H$.

In Eq. (5), $h_{\mathrm{s}}$ is the sensible heat and is defined as $h_{\mathrm{s}}=c_{\mathrm{p}} T$.

In Eq. (5), $\Delta H$ is the latent enthalpy of a cell. Since, in this case, a cell may consist of the semi-solid slurry, $\Delta H$ can be defined as

$$
\Delta H= \begin{cases}f_{1} L & \text { for } T \geqslant T_{\text {solidus }}, \\ 0 & \text { for } T<T_{\text {solidus }},\end{cases}
$$

where $L$ is the latent heat of fusion. The above definition of $\Delta H$ is in accordance with the latent enthalpy values of a cell in the slurry region. The calculation of the term $\Delta H$ involves the instantaneous liquid fraction, which is now predicted by the solution of the solid fraction transport equation discussed subsequently. Using this definition of $H$ in Eq. (4), the energy conservation equation reduces to

$$
\begin{gathered}
\frac{\partial}{\partial t}\left(f_{\mathrm{s}} c_{\mathrm{ps}}+f_{\mathrm{l}} c_{\mathrm{pl}}\right)(\rho T)+\nabla \cdot\left(f_{\mathrm{s}} c_{\mathrm{ps}}+f_{1} c_{\mathrm{pl}}\right)(\rho \boldsymbol{u} T) \\
=\nabla \cdot\left\{\left(f_{\mathrm{s}} k_{\mathrm{s}}+f_{\mathrm{l}} k_{1}\right) \nabla T\right\} \\
-\left[\frac{\partial}{\partial t}\left(\rho f_{1} \Delta H\right)+\nabla \cdot\left(\rho f_{1} \boldsymbol{u} \Delta H\right)\right] .
\end{gathered}
$$

In the preceding equations, subscripts " $\mathrm{l}$ " and "s" refer to the liquid and solid phases, respectively, $\boldsymbol{u}$ is the continuum velocity vector; $T$ is the temperature; $p$ is the pressure; $c_{\mathrm{pl}}$ and $c_{\mathrm{ps}}$ are specific heats of the liquid and solid phases, respectively; $k_{1}$ and $k_{\mathrm{s}}$ are thermal conductivities of the liquid and solid phases, respectively, $\rho$ is the continuum density; $\mu$ is the viscosity of the melt; $\beta_{\mathrm{T}}$ and $\beta_{\mathrm{S}}$ are the thermal and solutal coefficients of volumetric expansion, respectively. The terms $f_{1}$ and $f_{\mathrm{s}}$ denote mass fractions of the liquid and solid phases, respectively, to be calculated separately by the solid fraction transport equation. The continuum density is defined as

$\rho=g_{\mathrm{s}} \rho_{\mathrm{s}}+g_{1} \rho_{1}$,

where $g_{\mathrm{s}}$ is the volume fraction of solid and $g_{1}$ is the volume fraction of liquid. Similarly, the continuum velocity is defined as 
$\boldsymbol{u}=f_{\mathrm{s}} \boldsymbol{u}_{\mathrm{s}}+f_{1} \boldsymbol{u}_{1}$.

In implementing the preceding equations, we make an extended Boussinesq approximation by neglecting solidification shrinkage and assume that the important density changes are those associated with the buoyancy in the slurry. Since shrinkage-induced flow is neglected, the symbols $f_{1}$ and $g_{1}$ are equivalent and can be used interchangeably in the subsequent analysis.

\subsection{Transport of fragmented dendrites}

The electromagnetic stirring will shear off the dendrites from the solidification front and transport them in the melt. At the same time, solid fraction is continuously generated at the interface because of cooling from the sides. Hence the solid fraction in a control volume can be viewed as coming from two sources namely, from transport of solid fraction and generation of solid fraction by cooling. When there is no advection of the dendrites/solid particles, the solid fraction in a control volume can be predicted by the coupling between thermal and solute fields. However, in the present case, the electromagnetic stirring causes breaking of dendrites and subsequent advection of solid fraction throughout the domain. Hence, in a typical control volume, one has to perform a solid fraction mass balance by considering solid fraction generation (as a result of solidification) as well as advection to or from a neighboring control volume. The former component (solid fraction generation) can be predicted by a coupling between thermal and solute fields. The latter component, however, is absent in usual solidification problems in which dendrites are attached to the interface and a mushy region exists between the solidus and liquidus fronts. Hence, in the present case, the overall solid fraction balance in a control volume is represented by a conservation equation described subsequently.

Specifying the total solid fraction in a cell as

$f_{\mathrm{s}}=$ Solid fraction due to transport

$$
+ \text { Solid fraction due to generation }\left(f_{\mathrm{sg}}\right),
$$

the governing equation for mass conservation for the solid phase can be written as

$$
\frac{\partial}{\partial t}\left(\rho_{\mathrm{s}} f_{\mathrm{s}}\right)+\nabla \cdot\left(\rho_{\mathrm{s}} \boldsymbol{u}_{\mathrm{s}} f_{\mathrm{s}}\right)=f_{\mathrm{s}} \dot{M}_{\mathrm{s}},
$$

where $\dot{M}_{\mathrm{s}}$ is the rate of production of the solid phase. We are assuming that in the semi-solid slurry, the solid velocity, $\boldsymbol{u}_{\mathrm{s}}$, and the liquid velocity, $\boldsymbol{u}_{\mathrm{l}}$, are equal. It is also assumed that the liquid and solid phases have the same density. This simplification allows us to model the transport of solid fraction by considering a volume averaged velocity $\boldsymbol{u}$. By doing so, we are able to calculate the solid fraction explicitly in a control volume with a single-phase model that would otherwise require a two-phase model. Writing the right hand side of the above equation as generic source term, Eq. (12) becomes

$\frac{\partial}{\partial t}\left(\rho f_{\mathrm{s}}\right)+\nabla \cdot\left(\rho \boldsymbol{u} f_{\mathrm{s}}\right)=S_{\mathrm{g}}$

where $S_{\mathrm{g}}$ can be expressed as

$S_{\mathrm{g}}=\frac{\partial}{\partial t}\left(\rho f_{\mathrm{sg}}\right)$.

The second term on the left hand side represents the advected solid fraction because of stirring and $S_{\mathrm{g}}$ is the source term due to generation of solid fraction. The calculation of the source term, $S_{\mathrm{g}}$, and its numerical implementation is presented below.

The solid fraction component in a cell (due to solidification only) at any instance of time is given as

$f_{\mathrm{sg}}=-\frac{\Delta H_{\mathrm{g}}}{L}$,

where $\Delta H_{\mathrm{g}}$ accounts for the latent heat due to phase change in a control volume. The calculation of $\Delta H_{\mathrm{g}}$ is performed using the enthalpy update scheme as given subsequently by Eq. (30).

Therefore, the change in solid fraction between two instances of time owing to solidification can be expressed as

$\Delta f_{\mathrm{sg}}=-\frac{\Delta\left(\Delta H_{\mathrm{g}}\right)}{L}$.

The corresponding change in liquid fraction because of solidification is

$\Delta f_{\mathrm{lg}}=-\Delta f_{\mathrm{sg}}=\frac{\Delta\left(\Delta H_{\mathrm{g}}\right)}{L}$,

where

$\Delta\left(\Delta H_{\mathrm{g}}\right)=\Delta H_{\mathrm{g}}-\Delta H_{\mathrm{go}}$.

In the above equation, $\Delta H_{\mathrm{g}}$ and $\Delta H_{\mathrm{go}}$ are the latent enthalpy values (due to solidification only) at current and previous times, respectively. Hence, $S_{\mathrm{g}}$ can be given as $-\frac{\rho}{L} \frac{\partial \Delta H_{\mathrm{g}}}{\partial t}$.

\subsection{Species conservation}

In this model we assume that dendritic solidification is occurring at the solid/liquid interface. The "interface", in this context, implies the boundary between the slurry and the solidified shell. For modeling this phenomenon, the solute conservation equation is written for a fixed columnar dendritic system in which the microsegregation is governed by Scheil's equation [16]. The present model assumes that the dendrites break off immediate after formation. The fragmented dendrites form a slurry in the mould, and the transport of this slurry is governed by the solid fraction transport Eq. (13).

The single-phase solute transport equation can be derived directly by considering a macroscopic solute 
balance in an arbitrary control volume. From such a balance the following equation can be written as:

$\frac{\partial}{\partial t}\left(\rho C_{\text {mix }}\right)+\nabla \cdot\left(\rho \boldsymbol{u} C_{1}\right)=\nabla \cdot\left(\rho_{\mathrm{s}} g_{\mathrm{s}} D_{\mathrm{s}} \nabla C_{\mathrm{s}}+\rho_{\mathrm{l}} g_{1} D_{1} \nabla C_{\mathrm{l}}\right)$,

where $C_{\text {mix }}$ is a representative value obtained by space averaging over a volume defined on the microscopic scale. Representing this microscopic volume by $V=V_{\mathrm{s}}$ (volume of the solid fraction) $+V_{1}$ (volume of the liquid fraction), the general form of $C_{\text {mix }}$ can be written as

$C_{\text {mix }}=\frac{\int \rho_{1} C_{1} \mathrm{~d} V_{1}+\int \rho_{\mathrm{s}} C_{\mathrm{s}} \mathrm{d} V_{\mathrm{s}}}{\rho V}$.

In the present model, the solid particles (fragmented dendrites) are assumed to be dispersed throughout the liquid. It is assumed that within the slurry region, all parts of the solid are in equilibrium with the surrounding fluid. Essentially the solid-liquid interface is distributed throughout the slurry region and the concentration of solute in the liquid and solid phases will be related via $C_{\mathrm{s}}=k_{\mathrm{p}} C_{\mathrm{l}}$. The assumed nature of the microstructure and solute redistribution mechanisms in the microscopic volume will determine the exact form of $C_{\text {mix }}$. Two limiting cases of solute redistribution are possible: complete mixing at the microscopic level, i.e., there are no concentration gradients within the solid or liquid at the microscopic level (lever rule model); and complete mixing in the liquid with no diffusion in the solid (Scheil model). The solid particles in a semi-solid slurry do not have any physical contact with each other, as they are separated by the liquid medium. Hence, diffusion between the solid particles is not possible. On noting that $V_{\mathrm{s}}=g_{\mathrm{s}} V$, and with the assumption of Scheil behavior [16], Eq. (20) for $C_{\text {mix }}$ becomes

$\rho C_{\text {mix }}=\rho_{\mathrm{l}} f_{\mathrm{l}} C_{\mathrm{l}}+\rho_{\mathrm{s}} \int_{0}^{g_{\mathrm{s}}} C_{\mathrm{s}} \mathrm{d} \alpha$,

where $\alpha$ is a dummy variable for carrying out the integration [11]. Also, with $C_{\mathrm{s}}=k_{\mathrm{p}} C_{1}$ at all points in the domain and using the above definition of $C_{\text {mix }}$ in Eq. (19), the single-phase solute conservation equation can be written as

$\frac{\partial}{\partial t}\left(\rho C_{1}\right)+\nabla \cdot\left(\rho \boldsymbol{u} C_{1}\right)=\nabla \cdot\left(D^{+} \nabla C_{1}\right)+S_{\mathrm{c}}$,

where $D^{+}$is the mass diffusion coefficient and $S_{\mathrm{c}}$ is the source term. For the present model with Scheil behavior

$D^{+}=\rho f_{1} D_{1}$,

$S_{\mathrm{c}}=\frac{\partial}{\partial t}\left(\rho f_{\mathrm{s}} C_{1}\right)-k_{\mathrm{p}} C_{1} \frac{\partial}{\partial t}\left(\rho f_{\mathrm{s}}\right)$,

where $k_{\mathrm{p}}$ is the partition coefficient and $C$ is the concentration of the solute.

\subsection{Lorentz force calculations}

The arrangement of the electromagnetic stirrer is shown in Fig. 1. Six conducting coils with 10 turns each are stacked around the mold in the electromagnetic stirrer. A three-phase alternating current with peak value of excitation current density of $10 \mathrm{~A} \mathrm{~mm}^{-2}$ and frequency of $5 \mathrm{~Hz}$ is passed through these conductors. Other physical data used for calculation of Lorentz force is shown in Table 2. The electromagnetic stirring system produces an axisymmetric travelling magnetic field, and gives rise to an axial component of the magnetic field $\left(B_{z}\right)$ and a radial component $\left(B_{r}\right)$ that combine with the eddy current to produce radial and axial components of the Lorentz force, $F_{r}$ and $F_{z}$, respectively. These Lorentz forces cause the fluid to ascend near the wall of the mold and descend near the centerline. The Lorentz forces are calculated by solving Maxwell's equations for which the magnetohydrodynamic form is given below:

$\nabla \times \mathbf{E}=-\frac{\partial \mathbf{B}}{\partial t}$,

$\nabla \times \mathbf{B}=\mu_{\mathrm{p}} \mathbf{J}$,

$\nabla \cdot \mathbf{B}=0$

and

$\nabla \cdot \mathbf{J}=0$,

where $\mathbf{E}$ is the electric field, $\mathbf{J}$ is the current density in the melt, $\mathbf{B}$ is the magnetic flux density, $t$ is the time and $\mu_{\mathrm{p}}$ is the magnetic permeability of the melt to be stirred. The Lorentz force term $\mathbf{F}$ in such flow is given as follows:

$\mathbf{F}=\mathbf{J} \times \mathbf{B}$.

The electric current density is governed by Ohm's law for a moving medium:

$\mathbf{J}=\sigma_{\mathrm{e}}(\mathbf{E}+\mathbf{u} \times \mathbf{B})$,

where $\sigma_{\mathrm{e}}$ is the electrical conductivity of the melt and $\mathbf{u}$ is the fluid velocity vector. Another assumption is made that the convective term $\mathbf{u} \times \mathbf{B}$ in Ohm's law can be neglected, based on the very low values of the Magnetic

Table 2

Data used for Lorentz force calculation

Length of the stirrer

Radius of the mould

Number of conducting coils

used in the stirrer

Current density of source current in the coils (peak)

Frequency of source current

Number of turns in each coils

Relative permeability of the melt

Resistivity of the melt
$100 \mathrm{~cm}$

$26.67 \mathrm{~cm}$

6

$10 \mathrm{~A} \mathrm{~mm}^{-2}$

$5 \mathrm{~Hz}$

10

1.0

$2.8 \times 10^{-8} \Omega \mathrm{m}$ 
Reynolds number [17]. This means that the Lorentz force field may be calculated by neglecting the fluid motion. The above equations are solved numerically using a commercially available finite element based package, FLUX2D.

\subsection{Initial and boundary conditions}

The boundary conditions consistent with the above set of differential equations used in the context of the geometry shown in Fig. 3 are as follows:

(a) Left boundary: $\frac{\partial u}{\partial r}=0, \frac{\partial T}{\partial r}=0, \frac{\partial C_{1}}{\partial r}=0$ and $\frac{\partial f_{\mathrm{s}}}{\partial r}=0$ (axisymmetric condition): $v=0$.

(b) Top surface: $u=u_{\text {in }}, v=0$ for inlet opening on the top surface; $u=0, v=0$ for other locations on the top surface; $T=T_{\mathrm{i}}, C_{1}=C_{\mathrm{i}}$ and $f_{\mathrm{s}}=0$.

(c) Bottom boundary: $u=-u_{\text {cast }}, v=0, \frac{\partial T}{\partial z}=0, \frac{\partial C_{1}}{\partial z}=0$ and $f_{\mathrm{s}}=1$.

(d) Right wall: If $T<T_{\text {solidus }} u=-u_{\text {cast }}, v=0, f_{\mathrm{s}}=1$; If $T \geqslant T_{\text {solidus }}, \quad u=0, \quad v=0, f_{\mathrm{s}}=0 ; \quad-k \frac{\partial T}{\partial r}=$ $\left.h\left(T-T_{\mathrm{amb}}\right)\right|_{r=R}, \frac{\partial C_{1}}{\partial r}=0$.

The heat transfer coefficients in the primary cooling zone are obtained from Reddy and Beckermann [13]. To model the spray cooling by water in the secondary cooling zone, correlations developed by Weckman and Niessen [18] are used.

The initial conditions appropriate to the physical situations are as follows:

At $t=0, \quad T=T_{i}, C_{\mathrm{l}}=C_{i}, f_{\mathrm{s}}=0$.

Boundary conditions for the Maxwell's equations used in calculation of Lorentz force field are as follows:

$\mathbf{J} \cdot \mathbf{n}=0 \quad$ at the walls

and the magnetic flux density $\mathbf{B}$ is continuous across the walls.

\section{Numerical procedure}

The governing transport equations are solved using a pressure-based finite volume method according to the SIMPLER algorithm [19]. A power-law scheme is used to evaluate the finite-volume coefficients. A tri-diagonal matrix algorithm (TDMA) solver is used to solve iteratively the resultant system of algebraic equations. The finite volume algorithm is suitably modified to account for phase change considerations in semi-solid casting. The broad steps of the numerical formulations are outlined in the flowchart presented in Fig. 4.

As mentioned earlier, the latent heat content of each control volume consist of two parts: one due to advection of dendritic fragments, and the other due to phase change within the control volume. For accurate predic- tions of the latter phenomenon, the latent heat component of each computational cell due to solidification needs to be updated according to the temperature predicted by the macroscopic conservation equations in each iteration within a time-step. In a physical sense, such an updating attempts to neutralize the difference in the nodal temperatures predicted by energy equation and that dictated by the phase-change considerations. In the present context, we choose an iterative update scheme proposed by Brent et al. [20] which is of the form

$$
\left[\Delta H_{\mathrm{Pg}}\right]_{n+1}=\left[\Delta H_{\mathrm{Pg}}\right]_{n}+\frac{a_{\mathrm{P}}}{a_{\mathrm{P}}^{0}} \lambda\left[\left\{h_{\mathrm{Pg}}\right\}_{n}-c_{\mathrm{p}} F^{-1}\left\{\Delta H_{\mathrm{Pg}}\right\}_{n}\right],
$$

where $a_{\mathrm{P}}^{0}=\rho \Delta V / \Delta t, a_{\mathrm{P}}$ is the coefficient of $T_{\mathrm{p}}$ in the discretization equation of the governing energy equation, $\lambda$ is a relaxation factor, and $F^{-1}$ is a suitable function depending on the phase-change morphology. Here, $\Delta V$ is the volume of a computational cell centered around the grid point $P, \Delta t$ is the time step chosen, and $h_{\mathrm{pg}}$ is the sensible enthalpy associated with the nodal point $P$. The physical meaning of the term $a_{\mathrm{P}} / a_{\mathrm{P}}^{0}$ is described in Brent et al. [20]. Guidelines to the choice of appropriate form of $F^{-1}$ are presented in Chakraborty and Dutta [21]. Representative $F^{-1}$ functions are given as follows:

$F^{-1}\left[\Delta H_{\mathrm{g}}\right]=\left\{\begin{array}{l}T_{\mathrm{m}} \text { for pure metal, } \\ T_{\mathrm{m}}-\left(T_{\mathrm{m}}-T_{\mathrm{L}}\right)\left(\frac{\Delta H_{\mathrm{g}}}{L}\right)^{\left(k_{\mathrm{p}}-1\right)} \\ \text { for a binary alloy, with Scheil's behavior, }\end{array}\right.$

where $T_{\mathrm{m}}$ is the melting temperature of pure solvent, $T_{\mathrm{L}}$ is the liquidus temperature of $\mathrm{Al}-4.5 \mathrm{wt} \% \mathrm{Cu}$ alloy, $\Delta H_{\mathrm{g}}$ accounts for the latent heat only due to phase change in a control volume and $k_{\mathrm{p}}$ is the partition coefficient.

A comprehensive grid-independence study is undertaken to determine the appropriate spatial discretization, temporal discretization, and iteration convergence criteria to be used. As an outcome of this study, we have taken $80 \times 60$ non-uniform grids for our final simulation. Smaller grid sizes $(2.5 \mathrm{~mm} \times 4.5 \mathrm{~mm}$ approximately) are used in the mold region in an effort to resolve the large solid fraction, velocity, temperature, and species concentration gradients. A relatively coarse grid ( $15 \mathrm{~mm} \times 4.5 \mathrm{~mm}$ approximately) is taken in the lower portion of the domain where a fully solid region is expected to be present and diffusion is the only mode of transport. It is found that a finer grid system does not alter the results appreciably.

\section{Results and discussion}

Numerical simulations are carried out to study the transport phenomena in direct chill continuous casting of semi-solid billets. For the present case study, an Al$4.5 \mathrm{wt} \% \mathrm{Cu}$ alloy is used for CFD simulation. A direct 




Fig. 4. A flowchart of the numerical algorithm.

comparison of the results of present model with previous results is not possible because of unavailability of any CFD model that predicts the velocity, temperature, species distribution and transport of fragmented dendrites in semi-solid billet casting in presence of EMS. Hence, for validating the code, we consider a case of conventional direct chill continuous casting of $\mathrm{Al}-4.5 \mathrm{wt} \%$ alloy without any forced stirring. The predicted radial variation of macrosegregation is plotted in Fig. 5 and compared with the experimental data given in Finn et al. [12], and with the simulation results of Reddy and Beckermann [13]. For the purpose of code validation, we have switched off the effect of electromagnetic stirring, and used the same process parameters, boundary condi- tions and grid sizes as in [13]. Without the existence of slurry in this case, the flow in the mushy zone is modeled as a porous medium flow as done by Reddy and Beckermann [13]. Fig. 5 reveals that the present prediction agrees well with the simulation results of Reddy and Beckermann [13]. Also, the predicted segregation pattern appears to be in reasonably good agreement with the experimental results of Finn et al. [12]. After the validation exercise, the model is extended to incorporate electromagnetic stirring and other resulting effects.

Fig. 6 shows the nature of Lorentz force in the mold. The figure is zoomed near the outer radius of the mold. The variation is shown at the two instances during a cycle i.e., at the start of a cycle (Fig. 6a) and at half cycle 


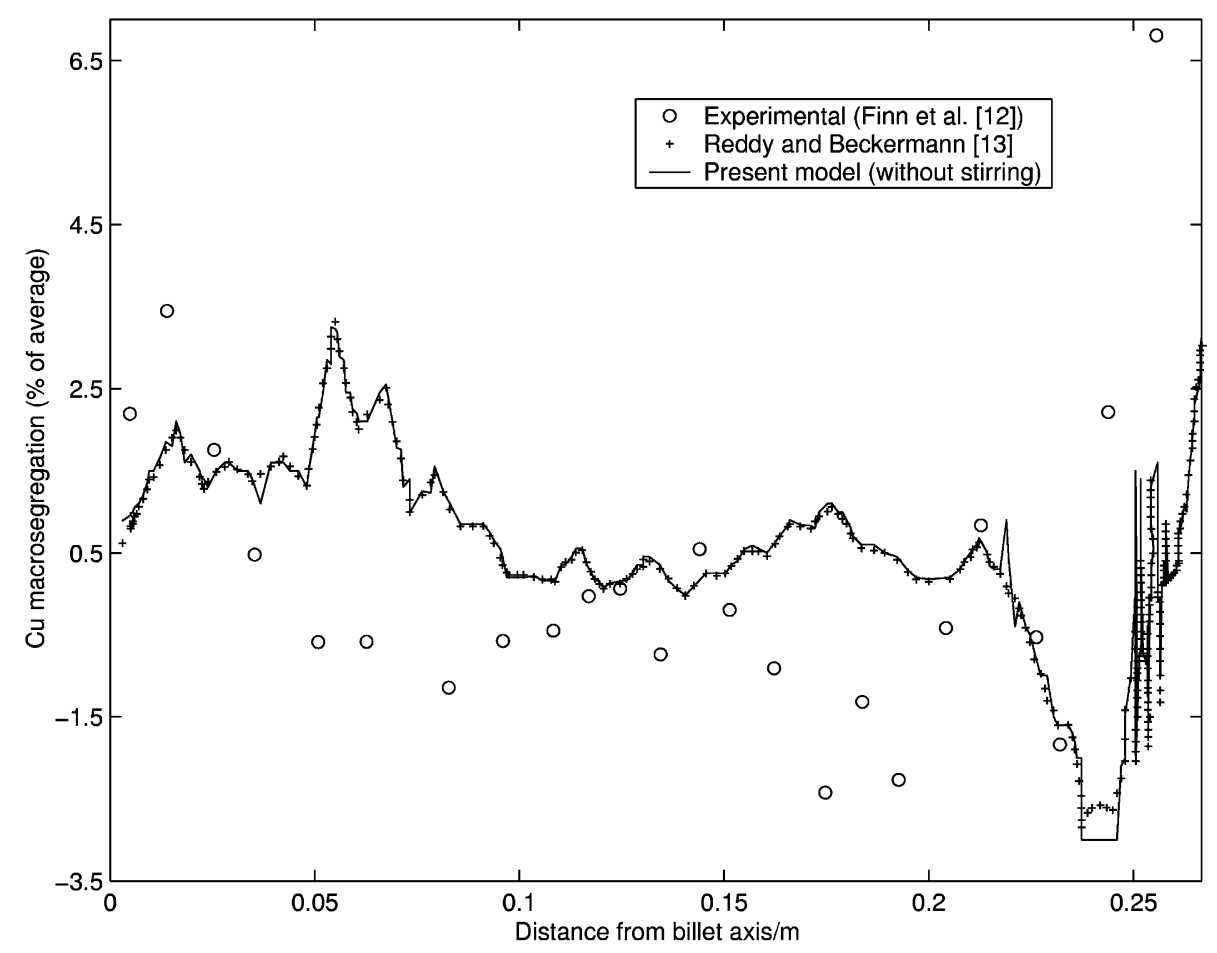

Fig. 5. Comparison of predicted radial macrosegregation.


Fig. 6. Variation of Lorentz force in the mold zoomed near the outer radius: (a) at start of cycle and (b) at half cycle time. 
time (Fig. 6b). The transient simulation with the given electromagnetic force field is carried out until a steady state is reached. Since the Lorentz force varies periodically with time due to the dynamic nature of electromagnetic field produced by EMS, a fully steady state is never reached. Instead, a stage is reached when the interface does not move up any further, and simply oscillates about a mean position. Hereafter, this stage will be referred to as the "steady state". This oscillation is observed in the numerical results, and the results presented in this manuscript are at particular instances of time after the "steady state" is reached. From the solid fraction contours we can get an idea of the location of the solid-liquid interface. The amplitude of this oscillation, measured in terms of the solid/liquid interface depth along the axis of the billet, is about $4 \mathrm{~mm}$ for the present case study.

Fig. 7a shows the corresponding stream-function pattern. Strong stirring produces circulation of the semisolid slurry inside the mold. The circulation makes the slurry ascend near the mold wall and descend along the axis. The maximum velocity is found to be $0.34 \mathrm{~m} \mathrm{~s}^{-1}$ corresponding to a maximum Lorentz force of $8.89 \mathrm{kN} \mathrm{m}^{-3}$. Fig. $7 \mathrm{~b}$ shows the steady state temperature distribution. It can be observed that temperature in the mold region is almost uniform because of the stirring action.

The strong fluid flow detaches the dendrites from the solid-liquid interface and churns the fragments in the mold to form a semi-solid slurry. Because of this stirring
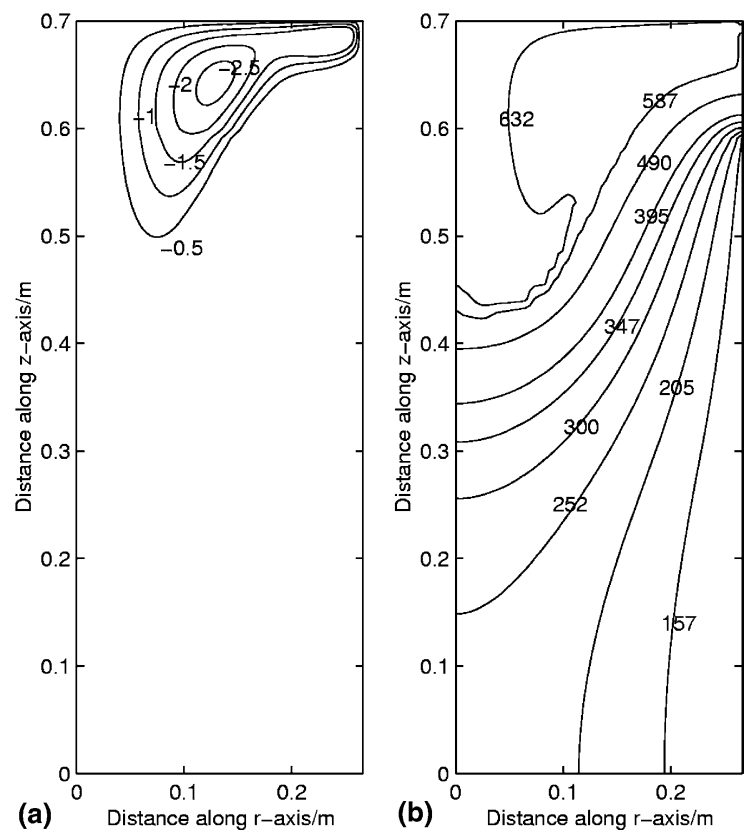

Fig. 7. (a) Stream-function distribution and (b) temperature distribution (in ${ }^{\circ} \mathrm{C}$ ). action, the distribution of solid fraction is also almost uniform in the mold region (Fig. 8a). Upon observing the solid fraction distribution during initial transients (not shown here), it is found that solidification progresses slowly at initial stages, and then reaches a steady rate in a short time. This is because of the fact that there is thorough mixing of the semi-solid slurry initially, and the presence of superheat in the melt retards the progress of solidification. After some time, when the bulk temperature of the semi-solid slurry decreases, solidification progresses faster and a steady state is reached subsequently. In reality, when this slurry solidifies, the microstructure is characterized by rounded, non-dendritic primary phase particles, separated and enclosed by near eutectic lower melting second phase. From the standpoint of prediction, the liquid composition of this second phase surrounding the primary phase is of particular importance, as it determines the reheat temperature for further processing of the semi-solid billet. As the direct chill semi-solid billet casting is a continuous process, the composition of the liquid near the solid-liquid interface will determine the final composition of the second phase in the billet. Hence, it is desirable to monitor the liquid composition in the second phase near the solid-liquid interface (e.g. near the 0.6 solid fraction contour) where stirring is arrested because of high viscosity. Fig. $8 \mathrm{~b}$ shows the liquid composition in the semi-solid slurry. It is observed that the strong stirring action, which advects the solute rejected at the solidliquid interface (due to partitioning), makes the solute
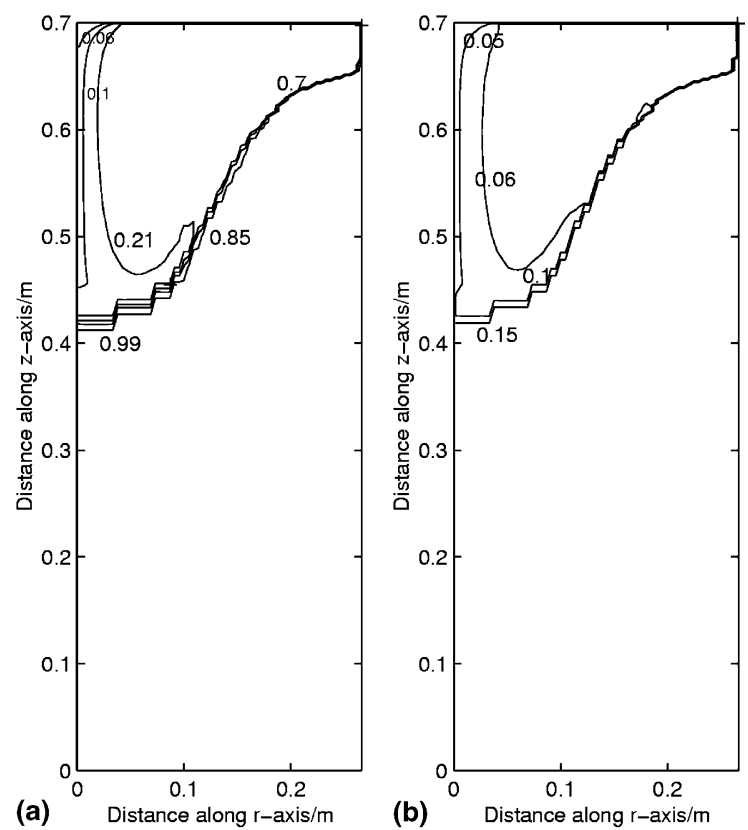

Fig. 8. (a) Solid fraction distribution and (b) composition distribution, showing concentration of $\mathrm{Cu}$. 


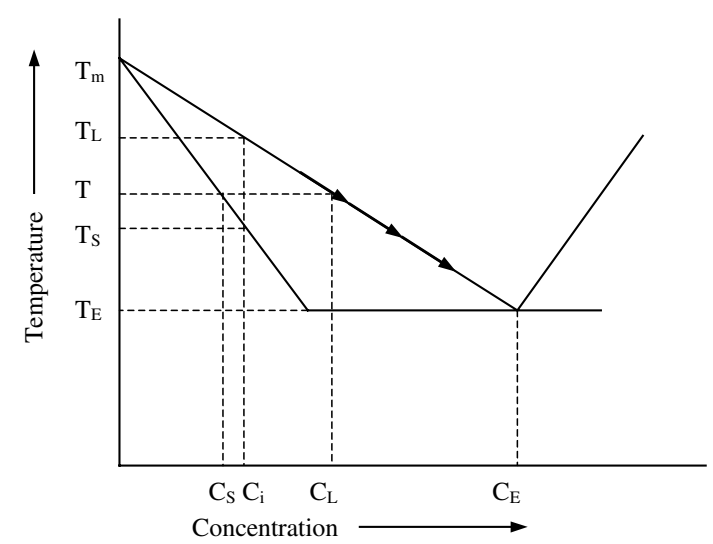

Fig. 9. A schematic phase diagram showing the solute enrichment in the remaining liquid during solidification.

composition nearly uniform in the core, while there is a composition gradient near the interface where the stirring is weaker. Thus, the continuous rejection of solute at the interface makes the remaining liquid more and more solute enriched, pushing the liquid composition towards the eutectic point. Hence, the solid that forms at later stages of solidification is of higher solute content. For the present case, with the process parameters given in Tables 1 and 2, it is found that the average copper concentration in the liquid near the interface is about 0.15 , which is a clear indication that the composition has shifted toward the eutectic point. Fig. 9 shows a schematic of this process. It is assumed here that for solid fractions of 0.6 or above, the slurry velocity is nearly zero because of extremely high viscosity. Hence we can assume that the last remaining liquid goes into the billet with the corresponding concentration $(\sim 15 \%$ in our case study). After entering the billet, this last remaining liquid will further solidify and part of it will terminate at the eutectic composition. In this study, however, we are predicting only the composition of the last remaining liquid as it enters the billet, which is an important outcome for use in a semi-solid process design.

The predicted radial variation of macrosegregation in the solidified billet after reaching steady state is plotted in Fig. 10a. For the case without stirring, the predicted segregation is positive towards the axis of the billet and negative towards the billet surface. This is caused by thermosolutal convection of solute-rich liquid towards the axis of the billet, thus creating a solute-lean
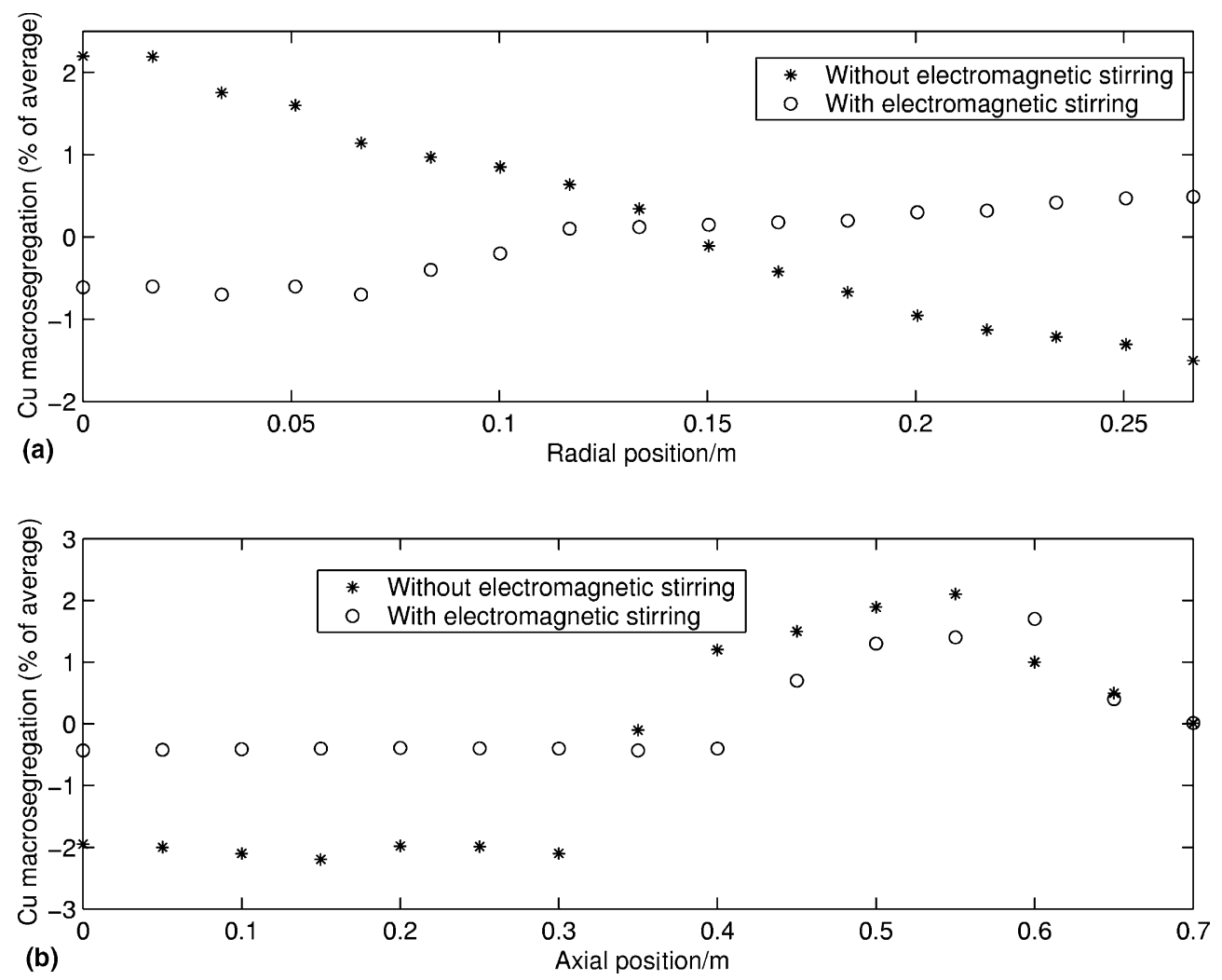

Fig. 10. Comparison of predicted macrosegregation with and without electromagnetic stirring: (a) final radial variation of macrosegregation in the solidified billet and (b) axial variation after the steady state. 
region near the billet surface. When stirring is applied, the forced circulation in the present case is in the opposite sense, causing the solute-rich and solute-lean regions to interchange. It is also observed that the overall macrosegregation pattern is better with forced stirring. Fig. 10b shows the axial variation of macrosegregation with and without stirring. It should be noted that the mixture composition near the solid-liquid interface determines the composition in the solidified billet. Hence, the axial variation of segregation inside the solidified billet, for a particular radial position, will be uniform. In the liquid region, however, there is variation in macrosegregation because of convection (Fig. 10b). Again, as expected, it is found that stirring results in better axial macrosegregation.

The effect of initial superheat on distribution of solid fraction in the mold is also studied. Three cases of superheat are discussed: low superheat $\left(30^{\circ} \mathrm{C}\right)$, medium superheat $\left(62^{\circ} \mathrm{C}\right)$ and high superheat $\left(80^{\circ} \mathrm{C}\right)$. The case with medium superheat corresponds to the base case study already presented. For this case, the distribution of solid fraction is presented in Fig. 8a. Fig. 11a and b shows the distribution of solid fraction with a high superheat and a low superheat, respectively. It is found that distribution of solid fraction is sensitive to the initial superheat. With a high superheat, most of the fragmented dendritic particles remelt due to high heat content of the liquid metal in the core. This phenomenon is reflected in the computational model with a

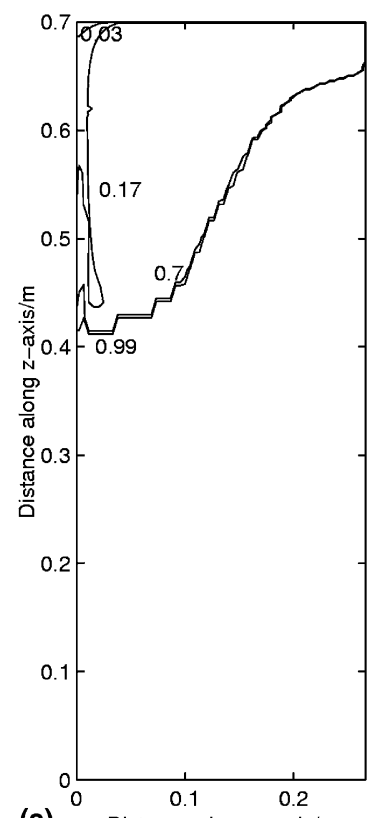

(a)

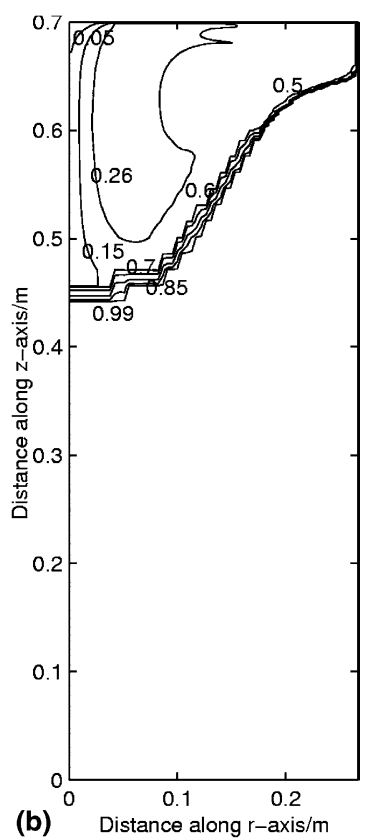

Fig. 11. Distribution of solid fraction with different initial superheats: (a) high superheat and (b) low superheat. near-uniform distribution of solid fraction in the mold (with an average value of 0.17 in this case). However, with a low superheat, there is a significant variation in solid fraction in the mold, as re-melting is poor. Near the top of the mold the distribution of solid fraction is again uniform (with an average value of 0.26 in this case), because of the relatively higher heat content of the inlet liquid metal.

The intensity of stirring depends primarily on the strength of the Lorentz force field produced by EMS. Fig. 12 shows the effect of stirring intensity (defined as the maximum magnitude of Lorentz force) on the average value of solid fraction in the slurry at steady state (with a fixed water flow rate of $0.116 \mathrm{~m}^{2} \mathrm{~h}^{-1}$, casting speed of $6.35 \times 10^{-4} \mathrm{~m} \mathrm{~s}^{-1}$ and superheat equal to that of the base case). It can be observed that the average value of solid fraction first increases with stirring intensity and then becomes a constant. The increase of solid fraction with stirring intensity is caused by an increase of the rate of transport of solid fraction from the solid-liquid interface. Increasing stirring intensity beyond a certain value (about $17 \mathrm{kN} \mathrm{m}^{-3}$ in the present case) does not cause any further increase in solid fraction, once the rate of removal of solid fraction equals the rate of its formation at the interface.

The position of the solid-liquid interface in the mold is important for an EMS system to function effectively. The interface shape and position determine the effective liquid domain in which the electromagnetic force field is to be distributed for a desired stirring action. Two of the most important factors on which the interface position depends are the stirring intensity and the applied cooling rate. Fig. 13 shows the variation of maximum depth of slurry zone (sump depth) with stirring intensity at steady state (with a fixed water flow rate of $0.116 \mathrm{~m}^{2} \mathrm{~h}^{-1}$, casting speed of $6.35 \times 10^{-4} \mathrm{~m} \mathrm{~s}^{-1}$ and superheat equal to that of the base case). Stirring produces better heat removal at the interface and causes the solid-liquid interface to shift upward. We can also observe that increasing stirring intensity beyond a certain value



Fig. 12. Effect of stirring intensity on the average solid fraction in the slurry. 


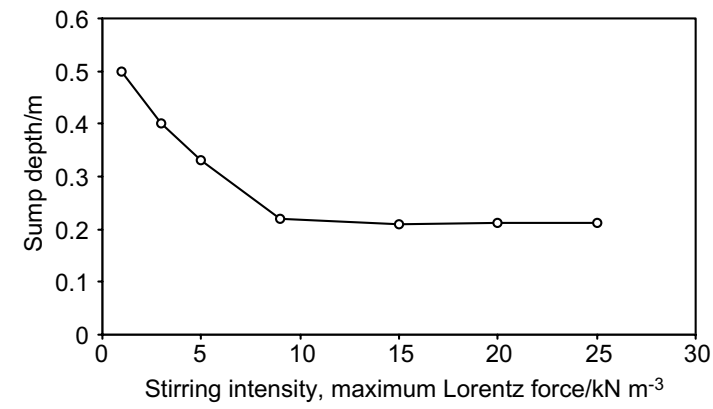

Fig. 13. Effect of stirring intensity on sump depth.



Fig. 14. Effect of cooling rate on sump depth.

(about $15 \mathrm{kN} \mathrm{m}^{-3}$ in the present case) does not cause any further upward shift of the solid-liquid interface. Based on this observation, it is not advisable to set the stirring intensity beyond a certain value, as it may not influence further change in the sump depth or in the average solid fraction value in the mold.

To study the effect of cooling rate on the interface location, simulations are carried out by varying the water flow rate in the cooling arrangement. The other parameters are kept constants i.e., a fixed stirring intensity of $8.89 \mathrm{kN} \mathrm{m}^{-3}$, a casting speed of $6.35 \times 10^{-4} \mathrm{~m} \mathrm{~s}^{-1}$ and superheat equal to that of the base case. Fig. 14 shows the variation of sump depth (maximum depth of solid-liquid interface) with cooling rate at steady state. It can be observed from this figure that the sump depth initially decreases sharply with increase in cooling rate, and then decreases gradually. With decrease of sump depth, the solid-liquid interface moves further away from the location of applied cooling in the secondary cooing zone (refer to Fig. 1). As a result, increase in cooling rate beyond a certain value does not have much effect in altering the depth of the sump.

\section{Conclusions}

A macroscopic model for numerical simulation of transport phenomena in direct chill casting of semi- solid billet in presence of electromagnetic stirring is presented. Electromagnetic stirring is used to shear off the dendrites from the solid-liquid interface. Simulations have been performed for the case of a binary alloy (Al- $4.5 \mathrm{wt} \% \mathrm{Cu}$ alloy). The proposed model predicts the temperature, velocity, species and the solid fraction distributions in the mold. It is found that the macroscopic behavior of casting of the semi-solid billets is sensitive to some of the process parameters such as initial superheat, stirring intensity and cooling rate. The present numerical model provides the basic foundation to study the transport phenomena associated with the semi-solid billet casting process, which is necessary for appropriate selection of parameters for the design of MHD stirring systems for which hardly any published literature is available.

\section{References}

[1] M.C. Flemings, Behavior of metal alloys in the semisolid state, Metall. Trans. B 22 (1991) 269-293.

[2] D.B. Spencer, R. Mehrabian, M.C. Flemings, Theoretical behavior of $\mathrm{Sn}-15$ pet $\mathrm{Pb}$ in crystallization range, Metall. Trans. 3 (1972) 1925-1932.

[3] C. Vives, Elaboration of semisolid alloys by means of new rheocasting processes, Metall. Mater. Trans. B 23 (1992) 189-206.

[4] M. Garat, S. Blais, C. Pluchon, W.R. Loue, Aluminium semi-solid processing: from billet to the finished part, in: A.K. Bhasin, J.J. Moore, K.P. Young, S. Midson (Eds.), Proc. 5th Int. Conf. on Semi-solid Processing of Alloys and Composites, Colorado, USA, 1998, pp. 199-213.

[5] J.P. Gabathuler, D. Barras, Y. Krahenbuhl, J.C. Weber, Evaluation of various processes for the production of billets with thixotropic properties, in: S.B. Brown, M.C. Flemings (Eds.), Proc. of the 2nd Intl. Conf. on Semi-solid Processing of Alloys and Composites, Boston, USA, 1992, pp. 33-46.

[6] J.J. Moore, Continuous Casting. The Application of Electromagnetic Stirring (EMS) in the Continuous Casting of Steel, vol. 3, Iron and Steel Society of AIME, Warrendale, PA, 1984, pp. 1-9.

[7] C. Vives, Elaboration of metal matrix composites from thixotropic alloy slurries using a new magnetohydrodynamic caster, Metall. Mater. Trans. B 24 (1993) 493-510.

[8] J.K. Roplekar, J.A. Dantzig, A study of solidification with a rotating magnetic field, Int. J. Cast Metals Res. 14 (2001) 79-95.

[9] P.J. Prescott, F.P. Incropera, The effect of turbulence in solidification of a binary metal alloy with electromagnetic stirring, Trans. ASME, J. Heat Transfer 117 (1995) 716724.

[10] J.C. Gebelin, C. Geindreau, L. Orgeas, P. Royer, D. Favier, J.L. Auriault, Influence of liquid flow through the solid skeleton on the overall deformation of metallic alloys in semi-solid state, in: G.L. Chairmetta, M. Rosso (Eds.), 6th Int. Conf. of Semi-solid Processing of Alloys and Composites, Turin, ITA, 2000, pp. 155-160. 
[11] V.R. Voller, A.D. Brent, C. Prakash, The modeling of heat, mass and solute transport in solidification systems, Int. J. Heat Mass Transfer 32 (9) (1989) 1719-1731.

[12] T.L. Finn, M.G. Chu, W.D. Bennon, The influence of mushy region microstructure on macrosegregation in direct chill cast aluminum-copper round ingots, in: C. Beckermann, L.A. Bertram, S.J. Pien, R.E. Smesler (Eds.), Micro/Macro Scale Phenomena in Solidification, HTDvol. 218/AMD-vol. 139, ASME, New York, 1992, pp. 1726.

[13] A.V. Reddy, C. Beckermann, Modeling of macrosegregation due to thermosolutal convection and contractiondriven flow in direct chill continuous casting of an $\mathrm{Al}-\mathrm{Cu}$ round ingot, Metall. Mater. Trans. B 28 (1997) 479-489.

[14] W.D. Bennon, F.P. Incropera, A continuum model for momentum, heat, and species transport in binary solidliquid phase change systems-I Model formulation, Int. J. Heat Mass Transfer 30 (16) (1987) 2161-2170.

[15] C. Prakash, V.R. Voller, On the numerical solution of continuum mixture model equations describing binary solid-liquid phase change, Numer. Heat Transfer 15 (1989) 171-189.

[16] M.C. Flemings, Solidification Processing, McGraw-Hill, New York, 1974, pp. 31-36.

[17] H.K. Moffatt, Electromagnetic stirring, Phys. Fluids A 3 (5) (1991) 1336-1343.

[18] D.C. Weckman, P. Niessen, A numerical simulation of the DC continuous casting process including nucleate boiling heat transfer, Metall. Trans. B 13 (1982) 593-602.

[19] S.V. Patankar, Numerical Heat Transfer and Fluid Flow, Hemisphere Publication, Washington, DC, 1980, pp. 131134.

[20] A.D. Brent, V.R. Voller, K.J. Reid, The enthalpy porosity technique for modeling convection-diffusion phase change: application to the melting of a pure metal, Numer. Heat Transfer 13 (1988) 297-318.

[21] S. Chakraborty, P. Dutta, A generalized formulation for evaluation of latent heat functions in enthalpy-based macroscopic models for convection-diffusion phase change processes, Metall. Mater. Trans. B 32 (2001) 562-564. 